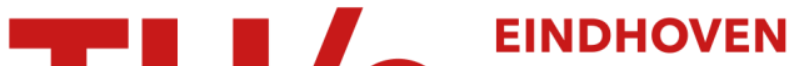 UNIVERSITY OF TECHNOLOGY
}

\section{The role of the silyl radical in plasma deposition of microcrystalline silicon}

\section{Citation for published version (APA):}

Smit, C., Swaaij, van, R. A. C. M. M., Hamers, E. A. G., \& Sanden, van de, M. C. M. (2004). The role of the silyl radical in plasma deposition of microcrystalline silicon. Journal of Applied Physics, 96(8), 4076-4083.

https://doi.org/10.1063/1.1790577

DOI:

10.1063/1.1790577

Document status and date:

Published: 01/01/2004

\section{Document Version:}

Publisher's PDF, also known as Version of Record (includes final page, issue and volume numbers)

\section{Please check the document version of this publication:}

- A submitted manuscript is the version of the article upon submission and before peer-review. There can be important differences between the submitted version and the official published version of record. People interested in the research are advised to contact the author for the final version of the publication, or visit the $\mathrm{DOI}$ to the publisher's website.

- The final author version and the galley proof are versions of the publication after peer review.

- The final published version features the final layout of the paper including the volume, issue and page numbers.

Link to publication

\section{General rights}

Copyright and moral rights for the publications made accessible in the public portal are retained by the authors and/or other copyright owners and it is a condition of accessing publications that users recognise and abide by the legal requirements associated with these rights.

- Users may download and print one copy of any publication from the public portal for the purpose of private study or research.

- You may not further distribute the material or use it for any profit-making activity or commercial gain

- You may freely distribute the URL identifying the publication in the public portal.

If the publication is distributed under the terms of Article 25fa of the Dutch Copyright Act, indicated by the "Taverne" license above, please follow below link for the End User Agreement:

www.tue.nl/taverne

Take down policy

If you believe that this document breaches copyright please contact us at:

openaccess@tue.nl

providing details and we will investigate your claim. 


\title{
The role of the silyl radical in plasma deposition of microcrystalline silicon
}

\author{
C. Smit ${ }^{\mathrm{a})}$ \\ Department of Applied Physics, Eindhoven University of Technology, P. O. Box 513, 5600 MB Eindhoven, \\ The Netherlands
}

R. A. C. M. M. van Swaaij b)

Delft University of Technology, DIMES-ECTM, P. O. Box 5053, 2600 GB Delft, The Netherlands

E. A. G. Hamers and M. C. M. van de Sanden

Department of Applied Physics, Eindhoven University of Technology, P. O. Box 513, 5600 MB Eindhoven, The Netherlands

(Received 10 May 2004; accepted 18 July 2004)

\begin{abstract}
Expanding thermal plasma chemical-vapor deposition has been used to deposit microcrystalline silicon films. We studied the behavior of the refractive index, crystalline fraction, and growth rate as a function of the silane $\left(\mathrm{SiH}_{4}\right)$ flow close to the transition from amorphous to microcrystalline silicon. It was found that the refractive index, a measure for film density, increases when the average sticking probability of the depositing radicals decreases. Furthermore, we studied the influence of the position at which $\mathrm{SiH}_{4}$ is injected in the expanding plasma on the film density. It was found that the film density becomes higher when the $\mathrm{SiH}_{4}$ is injected closer to the substrate. Both findings strongly suggest that the film density benefits from a high contribution of the $\mathrm{SiH}_{3}$ radical to the growth of microcrystalline silicon. (C) 2004 American Institute of Physics.

[DOI: 10.1063/1.1790577]
\end{abstract}

\section{INTRODUCTION}

Thin silicon films are widely applied in large-area electronic devices like flat displays and solar cells. Hydrogenated amorphous silicon $(a-\mathrm{Si}: \mathrm{H})$ has already been studied and applied since 1965. ${ }^{1}$ Quite some knowledge has been gained about the deposition mechanisms and the optimum plasma chemistry. ${ }^{2-6}$ It is now widely agreed that the $\mathrm{SiH}_{3}$ radical plays an important role in the deposition process of highquality $a-\mathrm{Si}: \mathrm{H}^{4,7}$ A higher surface mobility is often suggested as one of the reasons. ${ }^{8-10}$ Hydrogenated microcrystalline silicon $(\mu c-\mathrm{Si}: \mathrm{H})$ has become popular for application in large-area electronics about ten years ago. There is still a lot of debate about the growth mechanism, and several growth mechanisms have been proposed, many of them inspired on the successful growth model of $a-\mathrm{Si}: \mathrm{H}^{11-13}$ It is not yet clear what the optimum deposition plasma chemistry should look like and which radicals contribute favorably to the growth of high-quality $\mu c-\mathrm{Si}: \mathrm{H}$.

The industry standard for the production of thin silicon films is radio-frequent plasma-enhanced chemical-vapor deposition (RF PECVD), but other techniques have been developed, mainly with the aim to increase the growth rate. Very-high frequency (VHF) PECVD, ${ }^{14}$ hot wire (HW) $\mathrm{CVD},{ }^{15,16}$ and electron cyclotron resonance (ECR) PECVD ${ }^{17}$ are some of the alternative techniques investigated. In this paper, $\mu c-\mathrm{Si}: \mathrm{H}$ films have been prepared using expanding thermal plasma (ETP) CVD. ${ }^{18}$ ETP CVD is a remote plasma

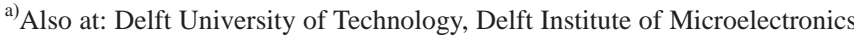
and Submicron Technology-Electronic Components, Technology and Materials, P. O. Box 5053, 2600 GB Delft, The Netherlands.

${ }^{\text {b) }}$ Author to whom correspondence should be addressed; electronic mail: r.vanswaaij@dimes.tudelft.nl
}

deposition technique, in which the plasma generation takes place in a relatively high pressure chamber (the cascaded arc plasma source), separate from the plasma chemistry that takes place when the precursor is injected in the low-pressure process chamber. This simplifies the chemistry to such an extent that ETP CVD is a suitable plasma deposition technique for the investigation of the influence of the plasma chemistry on the film deposition. This has been demonstrated, in particular, for the ETP CVD of $a-\mathrm{Si}: \mathrm{H}^{6}$ $a-\mathrm{C}: \mathrm{H}^{19}{ }^{19}$ and $a-\mathrm{SiO}_{x} \mathrm{C}_{y} \mathrm{H}_{z}{ }^{20}$

The deposition of thin silicon films with RF/VHF PECVD, HW CVD, and ETP CVD all rely on the decomposition of the precursor gas silane $\left.\left(\mathrm{SiH}_{4}\right)\right)$ into radicals and ions that eventually stick to the substrate surface, where film growth occurs. The decomposition mechanism of $\mathrm{SiH}_{4}$ is totally different for the three deposition techniques mentioned. In RF/VHF PECVD, electrons gain kinetic energy driven by the alternating electric field that is applied between two parallel electrodes, and the $\mathrm{SiH}_{4}$ molecules are dissociated by the electron impact. ${ }^{21}$ In HW CVD, the $\mathrm{SiH}_{4}$ molecules are dissociated by a catalytic reaction at hot tungsten or tantalum wires. In ETP CVD, a beam of atomic hydrogen is created, which interacts with the $\mathrm{SiH}_{4}$ molecules injected downstream. In this way, hydrogen abstraction reactions dominate the dissociation of $\mathrm{SiH}_{4}$, and it depends on the surplus of hydrogen and the path length to the substrate to what extent subsequent abstraction reactions are capable of creating the various silane radicals. ${ }^{5}$ These abstraction reactions are

$$
\begin{aligned}
& \mathrm{SiH}_{4}+\mathrm{H} \rightarrow \mathrm{SiH}_{3}+\mathrm{H}_{2}, \\
& \mathrm{SiH}_{3}+\mathrm{H} \rightarrow \mathrm{SiH}_{2}+\mathrm{H}_{2}, \\
& \mathrm{SiH}_{2}+\mathrm{H} \rightarrow \mathrm{SiH}+\mathrm{H}_{2},
\end{aligned}
$$




$$
\mathrm{SiH}+\mathrm{H} \rightarrow \mathrm{Si}+\mathrm{H}_{2} .
$$

The reaction rates of these reactions can be found in Refs. 22 and 23. Note that we neglect radical-radical as well as radical-silane reactions because we only consider here the high dilution conditions to deposit $\mu c-\mathrm{Si}: \mathrm{H}$. Furthermore, radical- $\mathrm{H}_{2}$ reactions are neglected because the reaction rate is very small. Since the $\mathrm{H}_{2}$-dilution is high, reactions involving ions can be neglected too $\left(<10^{16} \mathrm{~m}^{-3}\right){ }^{24}$

It has been demonstrated that for the deposition of highquality $a-\mathrm{Si}: \mathrm{H}$, it is required that the flux of $\mathrm{SiH}_{3}$ radicals toward the substrate dominates the deposition. In the deposition of high-quality $a-\mathrm{Si}: \mathrm{H}$ with ETP CVD, this is realized as follows. The $\mathrm{SiH}_{4}$ flow is set at a higher value than the flow of atomic hydrogen from the plasma source. The atomic hydrogen created in the cascaded arc plasma source is totally consumed by the first hydrogen abstraction reaction [Eq. (1)] with the relatively high density of $\mathrm{SiH}_{4} \cdot{ }^{5,25}$ Under these conditions, subsequent reactions of $\mathrm{SiH}_{3}$ with atomic hydrogen are suppressed and a dominant $\mathrm{SiH}_{3}$ beam is generated. The latter is confirmed by means of cavity ring-down spectroscopy (CRDS) and threshold ionization-mass-spectrometry measurements. ${ }^{25}$

It is generally accepted that for the deposition of $\mu c-\mathrm{Si}: \mathrm{H}$, atomic hydrogen is essential at the surface of the growing film to enhance the crystallzation. ${ }^{3,26,27}$ Therefore, commonly, the gas flows are adjusted to a high $(1 \%-5 \%)$ dilution of the $\mathrm{SiH}_{4}$ in $\mathrm{H}_{2}$ irrespective of the deposition technology. In RF PECVD, the high-energy electrons also dissociate $\mathrm{H}_{2}$. In $\mathrm{HW} \mathrm{CVD,} \mathrm{H}_{2}$ is catalytically dissociated at the tungsten or tantalum wire. In ETP CVD, increasing the $\mathrm{H}_{2}$ flow in the cascaded arc plasma source results in a higher atomic hydrogen flow into the reaction chamber, and a simultaneous decrease in $\mathrm{SiH}_{4}$ flow leads to a lower consumption of $\mathrm{H}$ by $\mathrm{SiH}_{4}$. Both effects result in a higher $\mathrm{H}$ flux at the surface of the growing film. As a consequence of the high atomic hydrogen density in the reaction chamber, the depletion of $\mathrm{SiH}_{4}$ is very high and can even reach $100 \%{ }^{18}$ Furthermore, subsequent hydrogen abstraction reactions will take place, creating $\mathrm{SiH}_{x}$ with $x<3$. This is clearly illustrated by the CRDS measurements by Hamers et al., in which the $\mathrm{SiH}_{4}$ flow is varied for a constant $\mathrm{Ar}$ and $\mathrm{H}_{2}$ flow. ${ }^{28}$

In general, $\mu c-\mathrm{Si}: \mathrm{H}$, especially when deposited at higher deposition rates and at lower temperatures, is porous to some extent, decreasing the applicability in solar cells. This characteristic we have discussed in another article. ${ }^{29}$ In principle, apart from the crystallite size, there will be no difference in the quality of the crystalline silicon phase in microcrystalline silicon. It is the amorphous phase between the crystallites that contains the pores and has the varying defect density. This suggests that the quality of $\mu c-\mathrm{Si}: \mathrm{H}$ can be improved when the $\mathrm{SiH}_{3}$ radicals dominate the deposition of microcrystalline silicon because the amorphous phase between the crystalline will be of better quality, similar to the case of entirely hydrogenated amorphous silicon films. Figure 1, in which we plotted the $\mu c-\mathrm{Si}: \mathrm{H}$ refractive index at a photon energy of $2 \mathrm{eV}$ versus the $\mathrm{SiH}_{4}$ depletion for various arc and reactor chamber settings, corroborates more or less this hypothesis. If the $\mathrm{SiH}_{4}$ depletion is close to $100 \%$, the reaction

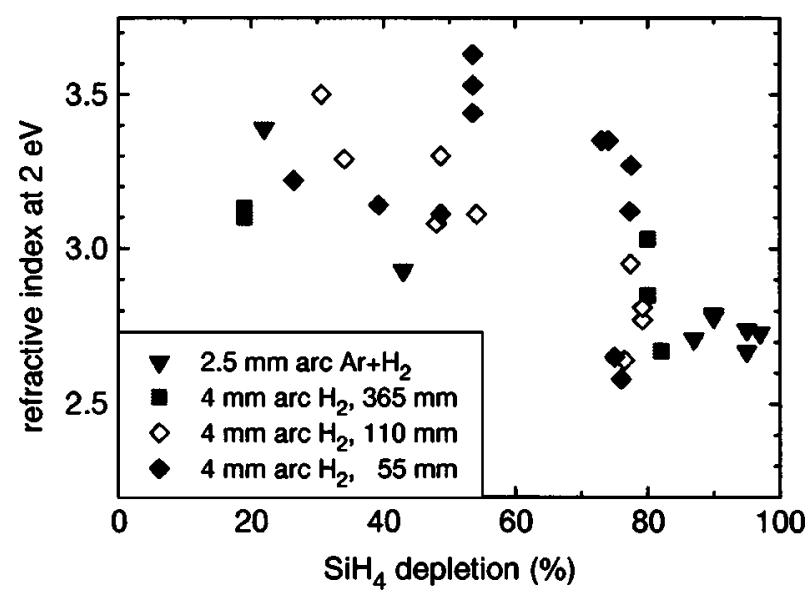

FIG. 1. Refractive index at $2 \mathrm{eV}$ vs the $\mathrm{SiH}_{4}$ depletion for various arc and process parameter settings. The legend indicates the type of plasma source, the applied gas mixture in the plasma source, and the distance of the $\mathrm{SiH}_{4}$ injection to the substrate (see Sec. II). Only the films with a crystalline fraction of 0.4 and higher are selected.

chain from Eqs. (1) and (4) goes to a full completion leading to a distribution of high sticking radicals and this is accompanied by a low refractive index.

In this paper, we will discuss two additional observations to Fig. 1, which were obtained during the systematic variation of the process conditions to achieve better quality $\mu c-\mathrm{Si}: \mathrm{H}$ (see Ref. 29). This discussion might give a leading principle in obtaining an even better quality $\mu c-\mathrm{Si}: \mathrm{H}$ in the near future. The first observation is related to the behavior of the refractive index, crystalline fraction, and growth rate as a function of the $\mathrm{SiH}_{4}$ flow, in particular, close to the $a-\mathrm{Si}: \mathrm{H} / \mu c-\mathrm{Si}: \mathrm{H}$ transition. The other observation discussed is related to the effect of the varying $\mathrm{SiH}_{4}$ injection ring position on the quality of the $\mu c-\mathrm{Si}: \mathrm{H}$.

We first describe the ETP CVD setup and the film diagnostics employed. Subsequently, the results are presented and discussed. As we will argue, the implications of the observations strongly suggest the beneficial role of the $\mathrm{SiH}_{3}$ radical in the deposition of $\mu c-\mathrm{Si}: \mathrm{H}$. Finally, the conclusions are presented.

\section{EXPERIMENTAL SETUP AND PROCEDURES}

The cascaded arc solar cell apparatus Delft Eindhoven (CASCADE) setup is designed to prepare thin-film silicon solar cells, in which the absorber layer is deposited using ETP CVD. ${ }^{30}$ It consists of a load lock, a RF PECVD chamber for the deposition of the doped layers, and a reaction chamber for the deposition of silicon films with the ETP CVD. In Fig. 2, a schematic representation is shown of ETP part of the CASCADE setup. This deposition technique has been extensively described elsewhere ${ }^{31}$ in the following discussions, we will give a brief summary and give the relevant process parameters, which are varied.

On top of the ETP reaction chamber is the cascaded arc plasma source. This source generates a plasma between three cathodes and an anode plate at a dc discharge current of $50 \mathrm{~A}$ at a pressure of about 0.1 bar. Two different geometries for the cascade arc plasma source have been employed. The 


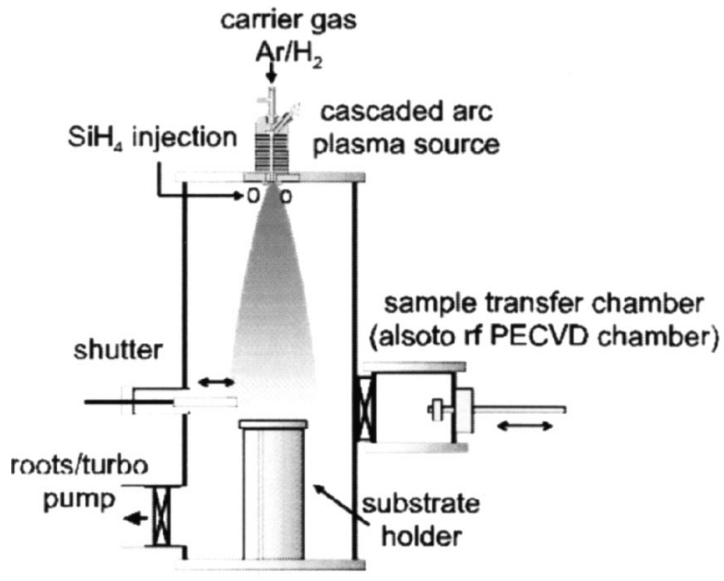

FIG. 2. ETP CVD chamber of the CASCADE setup. On top is the cascaded arc plasma source, which can be fed with different gases. In this case, $\mathrm{H}_{2}$ or an $\mathrm{Ar} / \mathrm{H}_{2}$ mixture is used (100-300 mbar). The plasma expands into the reaction chamber $\left(\sim 0.2\right.$ mbar), and downstream, the precursor gas $\mathrm{SiH}_{4}$ is injected. The silicon film is deposited on the substrate, which is on a temperature-controlled holder. A shutter is used in order to start the deposition at stable plasma conditions. On the side of the reaction chamber, below the substrate, the pump line is situated. A valve on the other side of the chamber opens the way to the load lock and the RF PECVD chamber.

first one consists of six copper cascade plates building up a discharge channel 30-mm long with a diameter of $2.5 \mathrm{~mm}$. The advantage of this source is that it can be operated at relatively low gas flows [typically $600 \mathrm{sccm}$ (denotes cubic centimeter per minute at stp) Ar and $200 \mathrm{sccm} \mathrm{H}_{2}$ ] and, therefore, a low pump capacity is sufficient to obtain the required process pressure of about 0.2 mbar. This source, referred to as the $2.5-\mathrm{mm}$ arc, cannot be operated on hydrogen gas only, but a minimum argon flow of twice the hydrogen flow must be added. In this research, this source is always operated at an argon-hydrogen flow ratio of $2: 1$, because for the deposition of microcrystalline silicon, the hydrogen dilution is important. In order to be able to operate a pure hydrogen plasma, a source with a different geometry is installed. The discharge channel is now created by four copper cascade plates with holes having a diameter of $4 \mathrm{~mm}$, forming a central channel of about 20-mm long. This source, referred to as the $4-\mathrm{mm}$ arc, is operated at $2000 \mathrm{sccm} \mathrm{H}_{2}$. The substrate is positioned at $410 \mathrm{~mm}$ below the plasma source exit. The substrate temperature is $300^{\circ} \mathrm{C}$ throughout this work, unless stated otherwise.

After leaving the nozzle of the cascaded arc, the plasma expands supersonically into the reaction chamber, which is at a pressure of about 0.25 mbar. The expanding plasma shocks when it collides with the background gas, after which it flows toward the substrate with a velocity that gradually decreases to about $100-200 \mathrm{~m} / \mathrm{s}$ right above the substrate. The precursor gas, $\mathrm{SiH}_{4}$, is injected into the expanding plasma through a ring-shaped (80-mm diameter) gas line, which is concentric with the reaction chamber, with holes $(1 \mathrm{~mm}$ diameter) pointing to the axis of the reaction chamber. The atomic hydrogen in the plasma dissociates the $\mathrm{SiH}_{4}$ molecules into radicals, ${ }^{5}$ which are deposited at the substrate at $410 \mathrm{~mm}$ below the plasma source exit. The consumption of the $\mathrm{SiH}_{4}$ by the hydrogen plasma is measured with a mass spectrometer, which is mounted on the side of the reactor at the substrate level.

Using the 2.5-mm arc fed with $1200 \mathrm{sccm}$ Ar and $600 \mathrm{sccm} \mathrm{H}$, a series of samples has been prepared with a varying $\mathrm{SiH}_{4}$, flow in order to investigate the behavior of the refractive index, crystalline fraction, and growth rate close to the $a-\mathrm{Si}: \mathrm{H} / \mu c-\mathrm{Si}: \mathrm{H}$ transition.

A second series of samples has been prepared using the 4-mm arc fed with $2000 \mathrm{sccm}$ of $\mathrm{H}_{2}$ to investigate the influence of the position of the injection ring. Three injection ring positions have been employed, 365, 110, $55 \mathrm{~mm}$ above the substrate (for brevity referred to as high, middle, and low injection ring position), and for any of these positions, the $\mathrm{SiH}_{4}$ flow is varied from 5 to $25 \mathrm{sccm}$. The same deposition series is repeated using a hydrogen gas flow of $1500 \mathrm{sccm}$ and the injection ring at the high and the low position.

The layers are simultaneously deposited on Coming 1737 glass substrates and $n$-type crystalline Si wafers. Care was taken to have the thickness of all the films in the range from 650 to $750 \mathrm{~nm}$. The films are analyzed using reflectiontransmission spectroscopy to determine the thickness and the refractive index at a photon energy of $2 \mathrm{eV}$. Raman spectroscopy was used to determine the crystalline fraction in the microcrystalline film, as described previously. ${ }^{32}$

\section{RESULTS AND DISCUSSION}

\section{A. $\mathrm{SiH}_{4}$ variation}

In most PECVD technique, there is a threshold dilution $R\left[R=\mathrm{H}_{2} /\left(\mathrm{H}_{2}+\mathrm{SiH}_{4}\right)\right]$ for the deposition of $\mu c-\mathrm{Si}: \mathrm{H}$ (e.g., Ref. 33). In Fig. 3, the results of the film series deposited using the $2.5-\mathrm{mm}$ arc are shown. From the crystalline fraction in Fig. 3(a), the transition region between the amorphous and microcrystalline material can be determined at a $\mathrm{SiH}_{4}$ flow somewhere in between 5 and $10 \mathrm{sccm}$, as is indicated by the dashed vertical line. In Fig. 3(b), the depletion is shown as a function of the $\mathrm{SiH}_{4}$ flow. For the small $\mathrm{SiH}_{4}$ flows $(<3 \mathrm{sccm})$, the depletion is almost $100 \%$ because there is a surplus of $\mathrm{H}$ available in the plasma to dissociate all the injected $\mathrm{SiH}_{4} \cdot\left(\mathrm{H}_{2}\right.$ dissociation degrees of $0.3 \%$ (Ref. 34) and $0.4 \%$ (Ref. 35) have been reported for an $\mathrm{Ar} / \mathrm{H}_{2}$ ratio of $6 / 1$ and for a pure $\mathrm{H}_{2}$ plasma, respectively. For $\mathrm{H}_{2}$ flow of $600 \mathrm{sccm}$, this corresponds to $\mathrm{H}$ flow of about 1.8 and $24 \mathrm{sccm}$, respectively. The $\mathrm{H}$ flow in this case with an $\mathrm{Ar} / \mathrm{H}_{2}$ ratio of 2 is expected to be in between these two flows.) When the $\mathrm{SiH}_{4}$ flow increases, the depletion decreases because, gradually, there is not enough $\mathrm{H}$ to decompose all $\mathrm{SiH}_{4}$. In Fig. 3(c), the deposition rate is shown as a function of the $\mathrm{SiH}_{4}$ flow. As the $\mathrm{SiH}_{4}$ flow increases, the growth rate increases because more depositing radicals are created. Note that there seem to be two distinct slopes in the graph: a steep slope for the data points with a low $\mathrm{SiH}_{4}$ flow $(\leqslant 3 \mathrm{sccm})$ and a less-steep slope for the higher flows.

The observation of the different slopes might be interpreted as follows. First, it could be argued that this is due to the varying mass density of the films, which is suggested by the varying refractive indices in Fig. 3(d). To exclude this, the mass density of the films is calculated using the infrared 


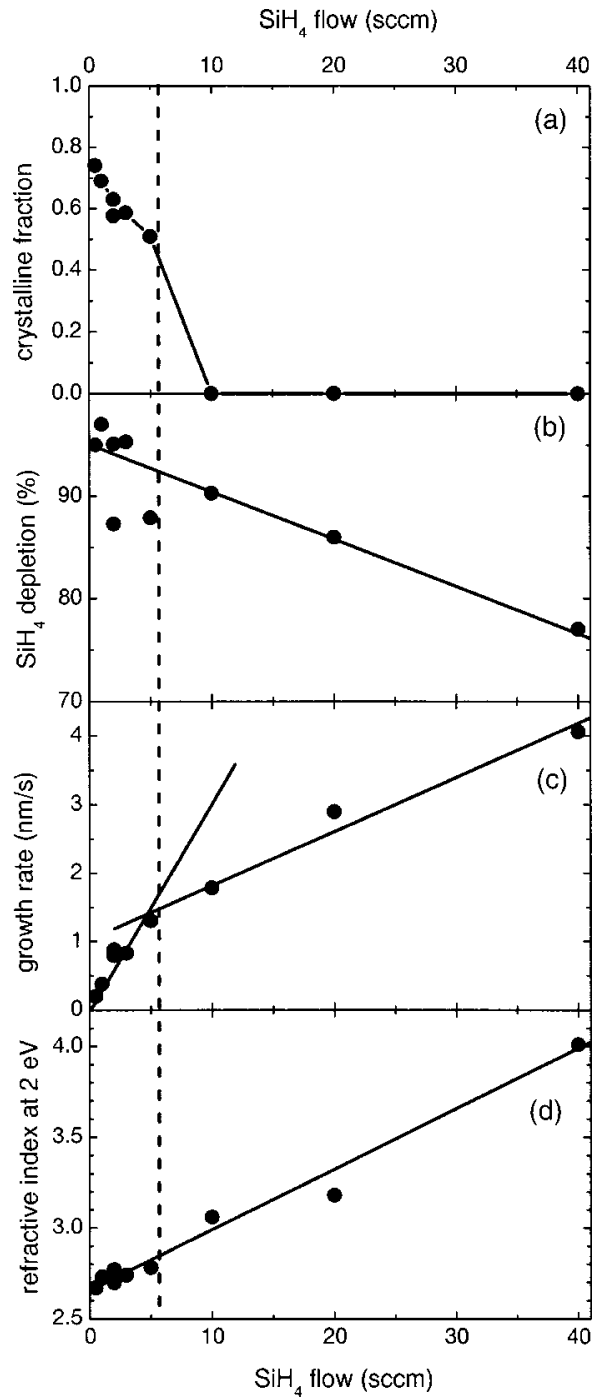

FIG. 3. (a) The crystalline fraction, (b) the $\mathrm{SiH}_{4}$ depletion, (c) the growth rate, and (d) refractive index as a function of the $\mathrm{SiH}_{4}$ flow. The Ar and the $\mathrm{H}_{2}$ flows are set at 1200 and $600 \mathrm{sccm}$, respectively. The vertical dashed line indicates the transition between the amorphous and microcrystalline silicon.

refractive index, the hydrogen content, and the crystalline fractions. ${ }^{36}$ From the mass density, the thickness, and the deposition time, the growth flux can be estimated. Furthermore, the $\mathrm{SiH}_{4}$ flow multiplied by the depletion [Fig. 3(b)] will give the rate at which the radicals $\left(\mathrm{SiH}_{x}\right.$ with $0 \leqslant x<4$, we neglect the production of higher radicals $\mathrm{Si}_{n} \mathrm{H}_{m}$ with $n>1)$ are produced and are eventually deposited. These two quantities are plotted in Fig. 4. The slope of the line through the data points in this graph indicates the number of $\mathrm{Si}$ atoms incorporated in the film per created $\mathrm{SiH}_{x}$ radical $(0 \leqslant x<4)$. This means that the slope is proportional to an effective, or averaged, sticking probability. In Fig. 5, we calculated the ratio of the growth flux and the radical production rate as a function of the $\mathrm{SiH}_{4}$ flow. The values plotted in Fig. 5 are proportional to the sticking probability. It is clear that the sticking probability is much higher for the low $\mathrm{SiH}_{4}$ flows than for the high $\mathrm{SiH}_{4}$ flows. This is due to the fact that for low $\mathrm{SiH}_{4}$ flows, follow-up hydrogen abstraction reactions creating $\mathrm{SiH}_{x}$ with $0 \leqslant x<3$ are more likely, and these radicals have sticking probabilities which are close to $1 .{ }^{10,37}$ The

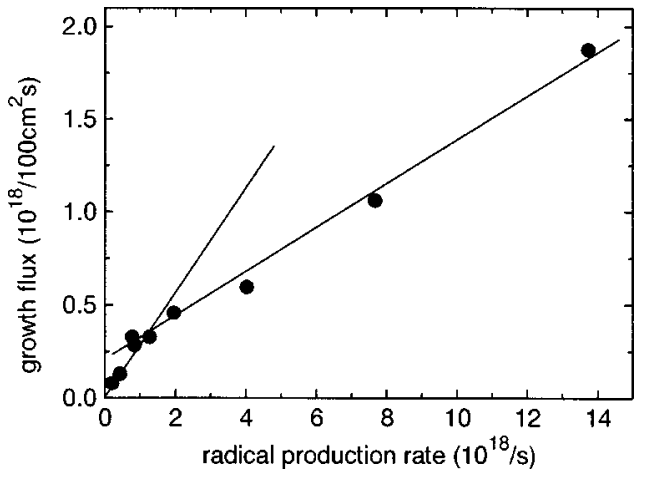

FIG. 4. Growth flux, calculated from the growth rate and the mass density of the film, as the number of particles that is deposited on the $100-\mathrm{cm}^{2}$ substrate in a second, vs the total rate of radical that are produced from the $\mathrm{SiH}_{4}$ in the reaction chamber, which is equal to the product of the depletion and the $\mathrm{SiH}_{4}$ flow. The slope of the graph is related to the sticking coefficient. Only a geometrical factor is missing because the deposition also takes place on the reactor walls.

values given in Fig. 5 do not directly correspond with the averaged sticking probability on the substrate. The material is also deposited on the walls of the reactor, although probably at lower rates than at the substrate. Therefore, the effective deposition area is larger than the substrate size of $100 \mathrm{~cm}^{2}$, which is used in the calculation of the growth flux. However, this geometrical factor will be constant as long as only the $\mathrm{SiH}_{4}$ flow is varied since the plasma expansion properties, and with it the spatial distribution of the radicals in the reaction chamber, remain unaltered.

We can go a step further by making an additional assumption for the low $\mathrm{SiH}_{4}$ flow. Under these conditions, we assume that $\mathrm{SiH}_{4}$ is entirely stripped of all hydrogen, i.e., the deposition is dominated by the silicon radical, which has a measured sticking coefficient of $1 .{ }^{10,37}$ Since we find values of about $0.4 / 100 \mathrm{~cm}^{2}$ in Fig. 5, a scaling factor of 2.5 should be introduced that corrects for the effective, growth-rateweighted deposition area. This scaling factor is introduced on the right-hand axis of Fig. 5. Consequently, for the highest $\mathrm{SiH}_{4}$ flows, a sticking coefficient of $2.5 \times 0.136=0.34$ is found. For comparison, the surface reaction probability of $\mathrm{SiH}_{3}$ is reported to be 0.28 (Ref. 38) and $0.30 .{ }^{37}$ Probably,

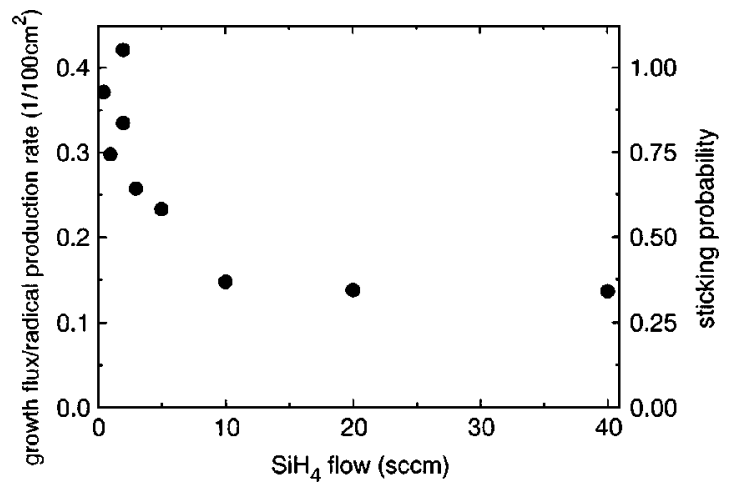

FIG. 5. Growth flux divided by the radical production is proportional to the sticking probability. Therefore, a decrease can be observed for increasing $\mathrm{SiH}_{4}$ flow because at higher $\mathrm{SiH}_{4}$ flow, less high-sticking radicals are produced. On the right axis, the scale is normalized to set the sticking coefficient for low $\mathrm{SiH}_{4}$ flows to 1 . 
for these high $\mathrm{SiH}_{4}$ flows, the $\mathrm{SiH}_{3}$ radicals contribute significantly to the deposition, although the contribution of other radicals is not yet fully minimized.

What are the implications of this observation? The refractive index in Fig. 3(d) shows a typical value of about 4 for good-quality $a-\mathrm{Si}: \mathrm{H}$ at a $\mathrm{SiH}_{4}$ flow of $40 \mathrm{sccm}$ at a growth rate of $4 \mathrm{~nm} / \mathrm{s}$. But when the $\mathrm{SiH}_{4}$ flow decreases, the refractive index also decreases, indicating that the material becomes porous. This also holds for the microcrystalline films. At a $\mathrm{SiH}_{4}$ flow of $5 \mathrm{sccm}$ (close to the transition to $a$ $-\mathrm{Si}: \mathrm{H}$ ), the refractive index is 2.8 [Fig. 3(d)]. At this $\mathrm{SiH}_{4}$ flow, the average sticking coefficient is 0.6 (Fig. 5). At the lowest $\mathrm{SiH}_{4}$ flows, the refractive index is 2.7 and the average sticking coefficient is almost 1 . This correlation between the average sticking coefficient and the refractive index strongly suggests that $\mathrm{SiH}_{3}$ plays a role in the improvement of the properties of the $a-\mathrm{Si}: \mathrm{H}$ tissue in between the crystalline material. However, keeping both the dilution high (and thus, a high $\mathrm{H}$ flux to the substrate to obtain the $\mu c-\mathrm{Si}: \mathrm{H}$ films) and, simultaneously, the $\mathrm{SiH}_{3}$ flux, relative to the other silane radicals (and thus, improve the quality of the $a-\mathrm{Si}: \mathrm{H}$ fraction in $\mu c-\mathrm{Si}: \mathrm{H})$, is a requirement that is hard to fulfill because $\mathrm{SiH}_{3}$ and $\mathrm{H}$ react with each other.

\section{B. Ring position variation}

How can we obtain a substantial contribution of the $\mathrm{SiH}_{3}$ radicals to the deposition of the film while simultaneously a high flux of atomic hydrogen to the substrate? This can be achieved by decreasing the interaction time of the injected $\mathrm{SiH}_{4}$ with the expanding hydrogen plasma. In this case, only one hydrogen abstraction reaction can take place before $\mathrm{SiH}_{3}$ is deposited at the substrate surface. With ETP CVD, this can be realized by injecting $\mathrm{SiH}_{4}$ into the expanding plasma close to the substrate (here we take $55 \mathrm{~mm}$ above the substrate). On injection, the $\mathrm{SiH}_{4}$ molecules will be dragged along with the plasma at a velocity of $100-200 \mathrm{~m} / \mathrm{s}$. The atomic hydrogen density is in the range of $10^{19}-10^{20} \mathrm{~m}^{-3}$. It can be estimated, based on the rates for reactions (1)-(4) reported in literature, that only a small fraction of the $\mathrm{SiH}_{3}$ radicals created in reaction (1) will react with the atomic hydrogen [reactions (2)-(4)] to form $\mathrm{SiH}_{x}$ with $0 \leqslant x<3$ before they reach the substrate surface.

In Fig. 6, the crystalline fraction, the $\mathrm{SiH}_{4}$ depletion in the plasma, the growth rate, and the refractive index are shown for the varying $\mathrm{SiH}_{4}$ flow and for the different injection ring positions. As can be seen from Fig. 6(a), the $\mathrm{SiH}_{4}$ flow at which the transition from $\mu c-\mathrm{Si}: \mathrm{H}$ to $a-\mathrm{Si}: \mathrm{H}$ occurs shifts to higher $\mathrm{SiH}_{4}$ flows for the lower injection position. This is a first indication that the plasma chemistry is influenced as the injection position is changed, resulting in a different film deposition mechanism. On the other hand, the refractive index does not seem to depend much on the $\mathrm{SiH}_{4}$ flow. However, if we look at the films containing an equal crystalline fraction, for example $50 \%$, then the refractive index increases from 3.1 to 3.4 if the injection position is decreased from 365 to $55 \mathrm{~mm}$ above the substrate [Fig. 6(d)]. This implies that the lowering of the $\mathrm{SiH}_{4}$ injection position improves the material properties of the $\mu c-\mathrm{Si}: \mathrm{H}$ deposited

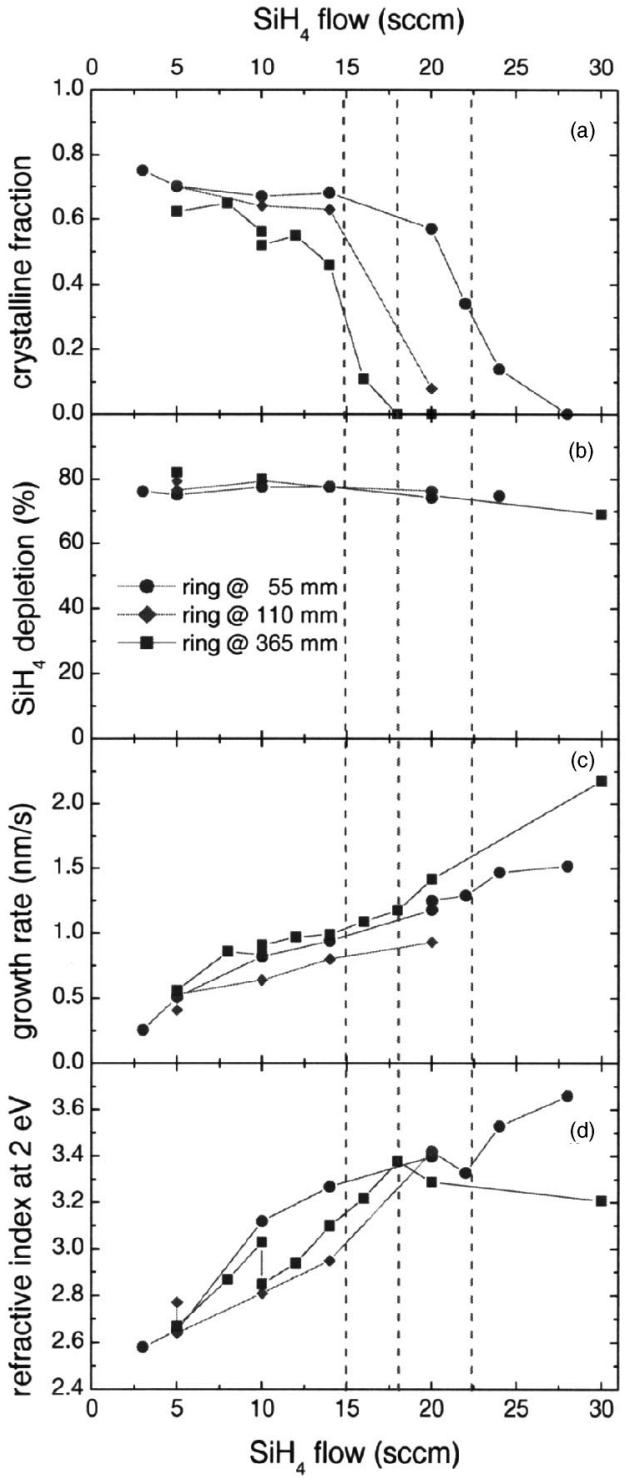

FIG. 6. (a) Crystalline fraction, (b) the $\mathrm{SiH}_{4}$ depletion, (c) the growth rate, and (d) the refractive index at $2 \mathrm{eV}$ as a function of the $\mathrm{SiH}_{4}$ flow during the deposition. The plasma source is fed with $2000 \mathrm{sccm}$ of $\mathrm{H}_{2}$. Three different injection ring positions are used, and in the legend, the distance above the substrate is indicated. The vertical dashed lines indicate the transition from microcrystalline to amorphous material (at 30\% crystalline fraction), the left-hand one is for the highest and the right-hand one for the lowest injection ring position.

under these conditions. Similar trends are observed for a hydrogen flow of $1500 \mathrm{sccm}$ and a varying injection ring position. The improvement of the $\mu c-\mathrm{Si}: \mathrm{H}$ properties is also reflected in the optoelectronic properties; for the lowest injection ring position, a photoresponse of 50 at a light conductivity of $10^{-6} \mathrm{~S} / \mathrm{cm}$ is obtained, whereas for the high injection ring position, the photo-and dark conductivity are almost equal at about $10^{-7} \mathrm{~S} / \mathrm{cm}^{29}$

These observations imply that the composition of the particle flux that arrives at the substrate surface depends on the injection position. To obtain more insight in the nature of the influence of the injection position on the mix of reactive species arriving at the substrate, we describe the deposition plasma with a simple plug-down model. ${ }^{39,40}$ In this model, we apply a number of simplifications for the sake of clarity. 


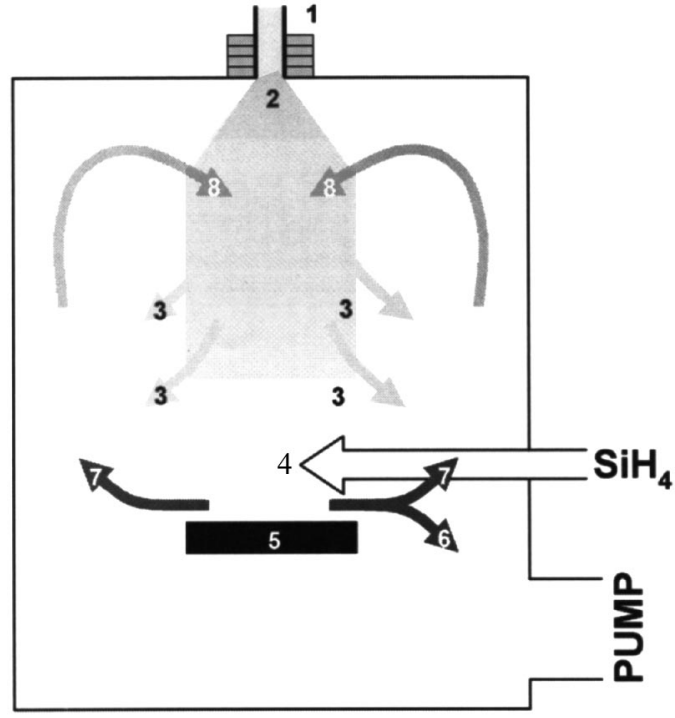

FIG. 7. Schematic of the model used for calculations. From the plasma source (1), atomic hydrogen flows to the substrate (5). $\mathrm{The}^{\mathrm{SiH}_{4}}$ is injected (white arrow) homogeneously in a plane (4) and reacts with the atomic hydrogen on the way toward the substrate. The deviations that form the simple model are also indicated. The hydrogen plasma expands, therefore, atomic hydrogen will also flow to the side of the reactor (3), where it reacts with the $\mathrm{SiH}_{x}$ that did not deposit on the substrate and was not pumped (6) but recirculates into the reactor (7). The reaction products can enter the plasma expansion (8) and find their way to the substrate again.

Therefore, the absolute values that result from the subsequent calculations might not be entirely correct, but the trends will provide a good illustration of the effect of the $\mathrm{SiH}_{4}$ injection position. We consider a parallel beam of atomic hydrogen having a uniform density of $10^{20} \mathrm{~m}^{-3}$ (valid for a hydrogen flow of about $2000 \mathrm{sccm}$ ) flowing toward the substrate with a velocity of $\nu=200 \mathrm{~m} / \mathrm{s}$. The heavy particle temperature in the plasma beam at substrate level is set at $600 \mathrm{~K}$. These values are obtained from two-photon absorption-laser-induced fluorescence ${ }^{41}$ and electron-beaminduced fluorescence ${ }^{35}$ measurements and mass spectrometry ${ }^{42}$ carried out on comparable plasmas. The gray column between the plasma source and the substrate in Fig. 7 represents this beam. In reality, the beam expands, resulting in a decreasing atomic hydrogen density going from the plasma source to the substrate. ${ }^{34}$ We approximate the $\mathrm{SiH}_{4}$ injection (with flow $Q=5 \mathrm{sccm}$ ) through the eight holes in the injection ring by a homogeneous injection in a plane with an area $A=64 \mathrm{~cm}^{2}$ parallel to the substrate surface, as indicated by the white arrow. Since there is no signature of the eight injection holes in the thickness variation of the deposited films, the injection can indeed be assumed to be uniform. This is explained by the fact that the thermal velocity (about $500 \mathrm{~m} / \mathrm{s}$ ) is higher than the drift velocity of the plasma expansion. The vertical position of the injection plane is allowed to vary. We assume that the $\mathrm{SiH}_{4}$ molecules instantaneously pick up the drift velocity of the plasma toward the substrate. Furthermore, we assume that the atomic hydrogen density is higher than the $\mathrm{SiH}_{x}$ density, so we can neglect the atomic hydrogen consumption and keep the density constant. The $\mathrm{SiH}_{4}$ depletion depends only slightly on the $\mathrm{SiH}_{4}$ flow [see Fig. 6(b)], which justifies this assumption. Furthermore,

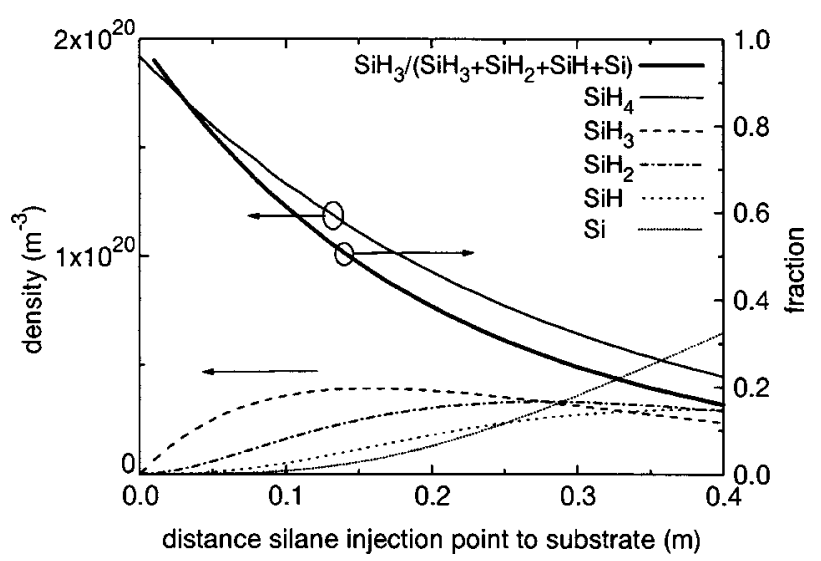

FIG. 8. Calculations of the densities of $\mathrm{SiH}_{4}$ and its related radicals for a hydrogen flow of $2000 \mathrm{sccm}$. Input: atomic hydrogen density $10^{20} \mathrm{~m}^{-3}$, flow velocity $200 \mathrm{~m} / \mathrm{s}$. $\mathrm{SiH}_{4}$ flow $5 \mathrm{sccm}$, and heavy particle temperature $600 \mathrm{~K}$. The atomic hydrogen density is assumed to be relatively high so that the consumption of atomic hydrogen does not influence its density. The bold line indicates the $\mathrm{SiH}_{3}$ radical density relative to the total radical density.

if the atomic hydrogen density decreases due to the reactions with $\mathrm{SiH}_{x}$, the reaction rates of reactions (1)-(4) will not change relative to each other, and the qualitative results of the model calculations are still valid.

In order to calculate the radical densities $\mathrm{SiH}_{x}$, the following set of differential equations has to be solved:

$$
\nu \frac{\partial n_{\mathrm{SiH}_{x-1}}}{\partial \mathrm{z}}=k_{x} n_{\mathrm{H}} n_{\mathrm{SiH}_{x}}-k_{x-1} n_{\mathrm{H}} n_{\mathrm{SiH}_{x-1}},
$$

in which $n$ is the density in $\mathrm{m}^{-3}\left(n_{\mathrm{SiH}_{x}}=0\right.$ for $x<0$ and $\left.x>4\right)$, $\nu$ is the drift velocity, and $z$ is the distance from the injection ring toward the substrate. The following boundary condition should be satisfied:

$$
n_{\mathrm{SiH}_{4}}(z=0)=\frac{Q N_{\alpha}}{V_{m} \nu A},
$$

in which $Q$ is the $\mathrm{SiH}_{4}$ mass flow (=5 sccm), $N_{\alpha}$ is Avogadro's constant $\left(6.022 \times 10^{23} \mathrm{~mol}^{-1}\right)$, and $V_{m}$ is the volume per mol $\left(24.5 \times 10^{-3} \mathrm{~m}^{3}\right)$.

The set of differential equations with all the relevant experimental parameters was solved using the MAPLE V software. In Fig. 8, the results of the calculation of the radi$\mathrm{cal}$ and the molecule densities at substrate level as a function of the distance of the injection ring to the substrate is shown. Clearly, the subsequent hydrogen abstraction reactions become more important as $\mathrm{SiH}_{4}$ is injected more remote from the substrate. $\mathrm{The}^{\mathrm{SiH}} 4$ density at substrate level decreases as the distance from the injection ring increases; the $\mathrm{SiH}_{3}$ density first increases, until the $\mathrm{SiH}_{4}$ density is so low that the production rate of $\mathrm{SiH}_{3}$ in reaction (1) is smaller than the consumption rate in reaction (2), and then decreases. Similar trends are shown for the $\mathrm{SiH}_{2}$ and $\mathrm{SiH}$ densities, and the $\mathrm{Si}$ density only increases with the distance between the injection ring and the substrate because there is no significant loss mechanism in the plasma for the Si radical. Note that we do not consider surface losses. Also shown in Fig. 8 is the ratio of the $\mathrm{SiH}_{3}$ radical density to the sum of the densities of the other radicals $\mathrm{SiH}_{x}$ with $0 \leqslant x<3$. It is clear that the closer 
the injection ring is to the substrate, the higher the $\mathrm{SiH}_{3}$ density, relative to the density of the other silane radicals, becomes.

The model described previously is a rather simple and linear model, and here, we want to investigate the limitations of the model using the experimental results from Fig. 6. The proposed model predicts a decrease in the $\mathrm{SiH}_{4}$ depletion as the injection position becomes lower (cf. $\mathrm{SiH}_{4}$ density in Fig. 8 ) because the interaction time with the atomic hydrogen is shorter. The experimental results, however, show hardly any influence: the depletion is about $80 \%$ for all applied injection positions. This immediately reveals the biggest weakness of the model: the recirculation of the particles in the reaction chamber is not accounted for. Recirculating $\mathrm{SiH}_{4}$ (and even $\mathrm{SiH}_{3}$, which is reflected at the substrate) will have a relatively long interaction path with $\mathrm{H}$ in the background gas and with the expanding plasma. This recirculating gas will generate $\mathrm{a} \mathrm{SiH}_{x}$ flux $(x<3)$ at the substrate surface, which partly masks the increase in the $\mathrm{SiH}_{3}$ flux due the lowering of the injection position. Therefore, the growth rate and the depletion are not significantly influenced by the injection position. Probably, a process chamber in which recirculation plays a smaller role (e.g., larger diameter of the reaction chamber or metal plates that block recirculating gas flows) can emphasize the influence of the injection position on the material properties and might even be the most promising way to further improve the quality of ETP CVD-deposited $\mu c$ $-\mathrm{Si}: \mathrm{H}$.

\section{CONCLUSIONS}

Two observations have been described in this paper. Firstly, the investigation of the growth rate as a function of $\mathrm{SiH}_{4}$ flow around the transition region between amorphous and microcrystalline material reveals that the average sticking coefficient of the depositing radicals decreases and the refractive index increases with increasing the $\mathrm{SiH}_{4}$ flow. Secondly, the material properties of $\mu c-\mathrm{Si}: \mathrm{H}$ improve when $\mathrm{SiH}_{4}$ is injected closer to the substrate, which can only be explained by a change in the radical composition at the substrate. A model that we applied to describe the deposition plasma indicates that there is a relative increase in the $\mathrm{SiH}_{3}$ radical flux when the injection position is closer to the substrate. These two observations strongly suggest that an increase in the contribution of $\mathrm{SiH}_{3}$ to the growth of $\mu c-\mathrm{Si}: \mathrm{H}$ improves the material quality.

\section{ACKNOWLEDGMENTS}

Ries van de Sande and Jo Jansen are acknowledged for the design and the construction of the deposition system and for their technical assistance. Martijn Tijssen and Arjan Driessen are acknowledged for their skillful technical assistance. This research was financially supported by NOVEM.

${ }^{1}$ H. F. Sterling and R. C. G. Swann, Solid-State Electron. 8, 653 (1965).

${ }^{2}$ A. Matsuda, K. Nomoto, Y. Takeuchi, A. Suzuki, A. Yuuki, and J. Perrin, Surf. Sci. 22, 50 (1990).

${ }^{3}$ J. Robertson, J. Appl. Phys. 87, 2608 (2000).

${ }^{4}$ W. M. M. Kessels, M. G. H. Boogaarts, J. P. M. Hoefnagels, M. C. M. van de Sanden, and D. C. Schram, J. Vac. Sci. Technol. A 19, 1027 (2001).
${ }^{5}$ M. C. M. van de Sanden, R. J. Severens, W. M. M. Kessels, R. F. G. Meulenbroeks, and D. C. Schram, J. Appl. Phys. 84, 2426 (1998).

${ }^{6}$ W. M. M. Kessels, A. H. M. Smets, D. C. Marra, E. S. Aydil, D. C. Schram, and M. C. M. van de Sanden, Thin Solid Films 383, 154 (2001). ${ }^{7}$ N. Itabashi, N. Nishiwaki, M. Magane, S. Naito, T. Goto, A. Matsuda, C. Yamada, and E. Hirota, Jpn. J. Appl. Phys., Part 1 29, 585 (1990).

${ }^{8}$ A. Gallagher, Mater. Res. Soc. Symp. Proc. 70, 3 (1986).

${ }^{9}$ A. Matsuda, J. Vac. Sci. Technol. A 16, 365 (1998).

${ }^{10}$ W. M. M. Kessels, M. C. M. van de Sanden, R. J. Severens, and D. C. Schram, J. Appl. Phys. 87(7), 3313 (2000).

${ }^{11}$ A. Matsuda, Thin Solid Films 337, 1 (1999).

${ }^{12}$ J. Robertson, J. Appl. Phys. 93, 731 (2003).

${ }^{13}$ K. Nakamura, K. Yoshino, S. Takeoka, and I. Shimizu, Jpn. J. Appl. Phys., Part 1 34, 442 (1995).

${ }^{14}$ U. Graf, J. Meier, U. Kroll, J. Bailat, C. Droz, E. Vaillat-Sauvain, and A. Shah, Thin Solid Films 427, 37 (2003).

${ }^{15}$ R. E. I. Schropp, Thin Solid Films 403-404, 17 (2002).

${ }^{16}$ D. H. Levi, B. P. Nelson, J. D. Perkins, and H. R. Moutinho, J. Vac. Sci. Technol. A 21, 1545 (2003).

${ }^{17}$ M. Pontoh, V. L. Dalal, and H. Gandhi, Mater. Res. Soc. Symp. Proc. 71, 521 (2002).

${ }^{18}$ C. Smit, E. A. G. Hamers, B. A. Korevaar, R. A. C. M. M. van Swaaij, and M. C. M. van der Sanden, J. Non-Cryst. Solids 299-302, 98 (2002).

${ }^{19}$ J. Benedikt, R. V. Woen, S. L. M. van Mensfoort, V. Perina, J. Hong, and M. C. M. van de Sanden, Diamond Relat. Mater. 12, 90 (2003).

${ }^{20}$ M. Creatore, M. Kilic, K. O'Brien, R. Groenen, and M. C. M. van de Sanden, Thin Solid Films 427, 137 (2003).

${ }^{21}$ W. Luft and Y. S. Tsuo, Hydrogenated amorphous silicon alloy deposition processes (Marcel Dekker Inc., New York, 1993).

${ }^{22}$ A. Goumri, W.-J. Yuan, L. Ding, Y. Shi, and P. Marshall, Chem. Phys. 177, 233 (1993)

${ }^{23}$ J. Perrin, O. Leroy, and M. C. Bordage, Contrib. Plasma Phys. 36, 1 (1996).

${ }^{24}$ M. J. de Graaf, R. Severens, R. P. Dahiya, M. C. M. van de Sanden, and D. C. Schram, Phys. Rev. E 48, 2098 (1993).

${ }^{25}$ W. M. M. Kessels, A. Leroux, M. G. H. Boogaarts, J. P. M. Hoefnagels, M. C. M. van de Sanden, and D. C. Schram, J. Vac. Sci. Technol. A 19, 467 (2001).

${ }^{26}$ H. Fujiwara, Y. Toyoshima, M. Kondo, and A. Matsuda, Mater. Res. Soc. Symp. Proc. 609, A2.1 (2000).

${ }^{27}$ I. Solomon, B. Drevillon, H. Shirai, and N. Layadi, J. Non-Cryst. Solids 164, 989 (1993).

${ }^{28}$ E. A. G. Hamers, A. H. M. Smets, C. Smit, J. P. M. Hoefnagels, W. M. M. Kessels, and M. C. M. van de Sanden, Mater. Res. Soc. Symp. Proc. 664, A4.2 (2001).

${ }^{29}$ C. Smit, A. Klaver, B. A. Korevaar, A. M. H. N. Petit, R. A. C. M. M. van Swaaij, and M. C. M. van de Sanden, Thin Solid Films (submitted).

${ }^{30}$ B. A. Korevaar, C. Smit, R. A. C. M. M. van Swaaij, A. H. M. Smets, W. M. M. Kessels, J. W. Metselaar, D. C. Schram, and M. C. M. van de Sanden, Proc. of 16th European Photovoltaic Solar Energy Conference, Glasgow, UK, 1-5 May 2000, B119.

${ }^{31}$ W. M. M. Kessels, R. J. Severens, A. H. M. Smets, B. A. Korevaar, G. J. Adriaenssens, D. C. Schram, and M. C. M. van de Sanden, J. Appl. Phys. 89, 2404 (2001).

${ }^{32}$ C. Smit, R. A. C. M. M. van Swaaij, H. Donker, A. M. H. N. Petit, W. M. M. Kessels, and M. C. M. van de Sanden, J. Appl. Phys. 94, 3582 (2003).

${ }^{33}$ R. E. Schropp and M. Zeman, Amorphous and microcrystalline silicon solar cells (Kluwer academic publishers, Dordrecht, The Netherlands, 1998).

${ }^{34}$ S. Mazouffre, M. G. H. Boogaards, J. A. M. van de Mullen, and D. C. Schram, Phys. Rev. Lett. 84, 2622 (2000).

${ }^{35}$ C. Smit, G. J. H. Brussaard, E. C. M. de Beer, D. C. Schram, and M. C. M. van de Sanden, Plasma Sources Sci. Technol. (submitted).

${ }^{36}$ Z. Remeš, M. Vaněček, P. Torres, U. Kroll, A. H. Mahan, and R. S. Crandall, J. Non-Cryst. Solids 227-230, 876 (1998).

${ }^{37}$ J. P. Hoefnagels, A. A. E. Stevens, M. H. G. Boogaarts, W. M. M. Kessels, and M. C. M. van de Sanden, Chem. Phys. Lett. 360, 189 (2002).

${ }^{38}$ J. Perrin, M. Shiratani, P. Kae-Nune, H. Videlot, J. Jolly, and J. Guillon, J. Vac. Sci. Technol. A 16, 278 (1998).

${ }^{39}$ G. M. W. Kroesen, D. C. Schram, and J. C. M. de Haas, Plasma Chem. Plasma Process. 10, 531 (1990).

${ }^{40}$ M. C. M. van de Sanden, R. Van den Bercken, and D. C. Schram, Plasma Sources Sci. Technol. 3, 511 (1994).

${ }^{41}$ S. Mazouffre, M. G. H. Boogaarts, I. S. J. Bakker, P. Vandan, R. Engeln, 
and D. C. Schram, Phys. Rev. E 64, 016411(2001).

2000.

${ }^{42}$ W. M. M. Kessels, Ph. D. thesis, Eindhoven University of Technology, 